

natureresearch

\title{
OPEN Acute restraint stress reverses impaired LTP in the hippocampal CA1 region in mouse models of Alzheimer's disease
}

Received: 19 December 2018

Accepted: 17 July 2019

Published online: 29 July 2019

\begin{abstract}
Ming Wang ${ }^{1,2}$, Vijay Sankar Ramasamy ${ }^{1,2}$, Manikandan Samidurai ${ }^{1,2}$ \& Jihoon Jo ${ }^{1,2,3}$
Acute stress facilitates long-term potentiation (LTP) in the mouse hippocampus by modulating glucocorticoid receptors and ion channels. Here, we analysed whether this occurs in mouse models of Alzheimer's disease (AD) with impaired LTP induction. We found that a brief 30 min restraint stress protocol reversed the impaired LTP assessed with field excitatory postsynaptic potential recordings at cornu ammonis 3-1 (CA3-CA1) synapses in both Tg2576 and 5XFAD mice. This effect was accompanied by increased phosphorylation and surface expression of glutamate A1 (GluA1) -containing $\alpha$-amino-3-hydroxy-5-methyl-4-isoxazolepropionic acid receptors (AMPARs). Moreover, enhanced LTP induction and GluA1 phosphorylation were sustained up to $4 \mathrm{~h}$ after the stress. Treatment with $200 \mathrm{nM}$ dexamethasone produced similar effects in the hippocampi of these mice, which supports the glucocorticoid receptor-mediated mechanism in these models. Collectively, our results demonstrated an alleviation of impaired LTP and synaptic plasticity in the hippocampal CA1 region following acute stress in the AD mouse models.
\end{abstract}

\begin{abstract}
Alzheimer's disease $(\mathrm{AD})$ is the most common form of dementia in the aging population, and sporadic late-onset $\mathrm{AD}$ accounts for most cases of $\mathrm{AD}^{1}$. The major hallmarks of the disease are progressive memory loss and the accumulation of amyloid- $\beta(\mathrm{A} \beta)$ in the brain ${ }^{2,3}$. $\mathrm{A} \beta$ disrupts synaptic plasticity and impairs memory by modulating the mechanisms controlling long-term potentiation (LTP) $)^{4,5}$.

LTP is the long-lasting increase in synaptic strength that can be induced by tetanic stimulation of afferent fibres $^{6,7}$. It is believed to reflect long-term changes in the synaptic efficacy. Thus hippocampal LTP is regarded as a cellular model of learning and memory ${ }^{6}$. LTP is triggered by high-frequency stimulation (HFS) in the cornu ammonis1 (CA1) area of the hippocampus, and requires postsynaptic activation of $N$-methyl-D-aspartate receptors (NMDARs) as well as surface insertion of $\alpha$-amino-3-hydroxy-5-methyl-4-isoxazolepropionic acid receptors $(\mathrm{AMPARs})^{8}$, the trafficking of which underlies excitatory synaptic plasticity ${ }^{9}$. The LTP-associated increases in AMPAR surface expression and synaptic strength have been attributed to the influx of $\mathrm{Ca}^{2+}$ through NMDARs and subsequent activation of protein kinase $\mathrm{A}$ and calcium/calmodulin-dependent protein kinase II (CaMKII). However, exogenously applied $\mathrm{A} \beta$ or amyloid precursor protein (APP) overexpression in AD mouse models induces the removal of AMPARs from synapses, resulting in impaired hippocampal LTP ${ }^{10-14}$. A $\beta$ impairs AMPAR trafficking and function by reducing the activation ${ }^{15}$ and synaptic distribution ${ }^{16}$ of CaMKII and by calcineurinand protein phosphatase-1-mediated dephosphorylation of AMPAR subunits ${ }^{17}$. A $\beta$ may also affect hippocampal LTP by either inducing NMDAR-mediated excitotoxicity ${ }^{18}$ or reducing NMDAR surface expression via endocytosis.

Impaired LTP and cognition in mouse models of $\mathrm{AD}$ is exacerbated by chronic stress ${ }^{19}$. Chronic stress also impairs hippocampal LTP in the dentate gyrus and CA1 in rats ${ }^{20,21}$, which is associated with reduced CaMKII
\end{abstract}

\footnotetext{
${ }^{1}$ NeuroMedical Convergence Lab, Biomedical Research Institute, Chonnam National University Hospital, Jebong-ro, Gwangju, 501-757, Republic of Korea. ${ }^{2}$ Department of Biomedical Sciences, BK21 PLUS Center for Creative Biomedical Scientists at Chonnam National University, Research Institute of Medical Sciences, Chonnam National University Medical School, Gwangju, 501-757, South Korea. ${ }^{3}$ Department of Neurology, Chonnam National University Medical School, Gwangju, 501-757, Republic of Korea. Ming Wang and Vijay Sankar Ramasamy contributed equally. Correspondence and requests for materials should be addressed to J.J. (email: Jihoon.Jo@jnu. ac.kr)
} 
a
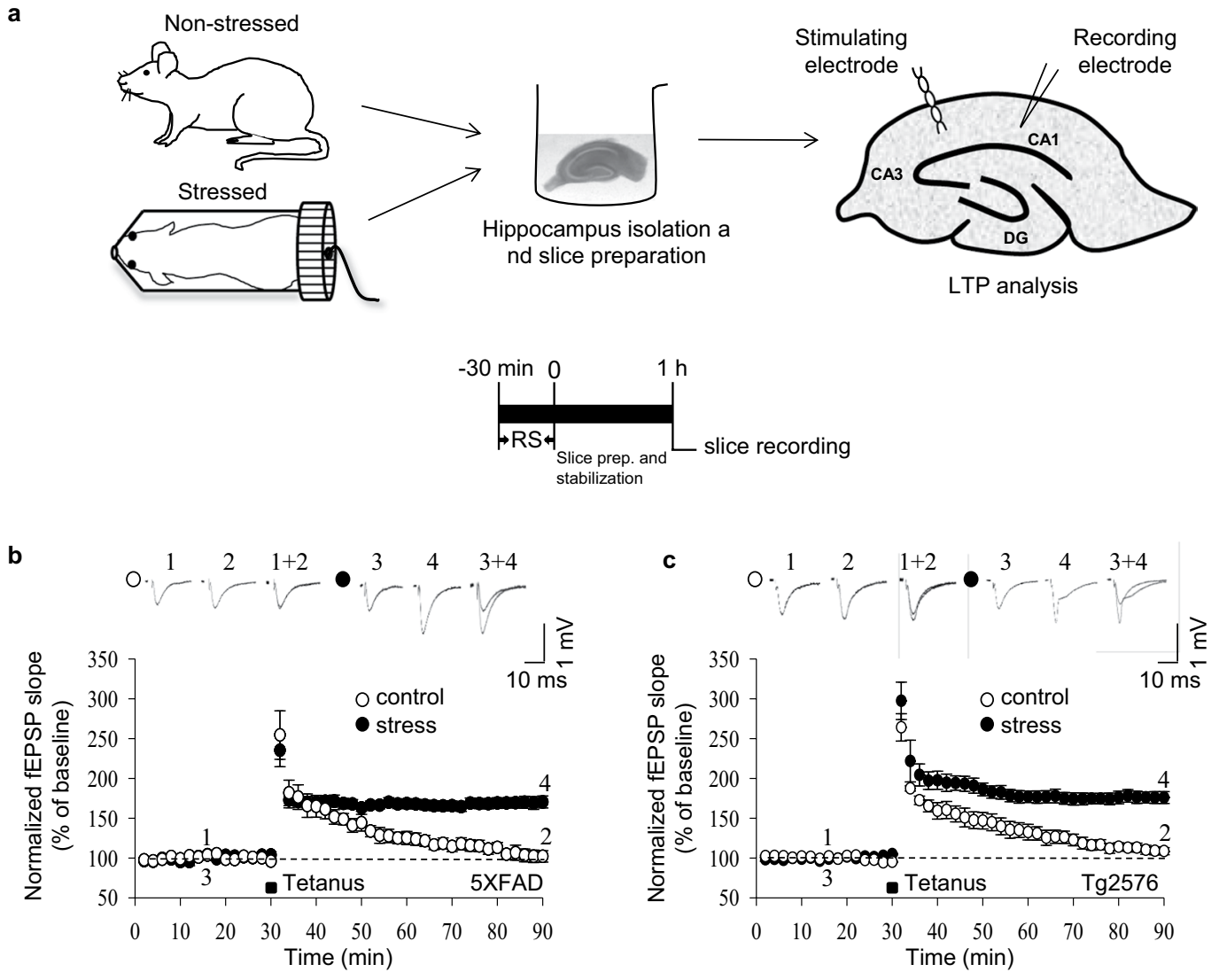

Figure 1. Acute stress rescues LTP impairment in AD mice. (a) Schematic diagram of the restraint stress protocol and field recording on a hippocampal slice. After $30 \mathrm{~min}$ of baseline recordings, LTP was induced in CA1 neurons with tetanic stimulation (two trains of $100 \mathrm{~Hz}, 100$ pulses; black square). Exposure to $30 \mathrm{~min}$ of restraint stress rescued impaired LTP in 5XFAD (b) and Tg2576 (c) mice. Error bars represent the SEMs $(n=6 /$ group).

levels ${ }^{22}$ and a selective decrease in AMPAR-mediated synaptic excitation ${ }^{23}$. The suppressed AMPAR and NMDAR expression and associated synaptic transmission lead to cognitive impairment ${ }^{24}$. By contrast, short or acute stress, such as the forced swim test and elevated plus maze task for $20 \mathrm{~min}$, facilitates NMDAR and AMPAR expression and glutamatergic transmission in rat prefrontal cortex, a brain region mainly involved in working memory ${ }^{25}$. Furthermore, acute stress exposure increases AMPAR surface expression and enhances LTP induction in the CA1 region of rat hippocampus ${ }^{26}$.

The present study was conducted to determine whether acute stress can reverse impaired hippocampal LTP in mouse models of $\mathrm{AD}$. We used restraint as a paradigm to induce acute stress ${ }^{27}$ in well-characterised transgenic mouse models, Tg2576 and 5XFAD, which express genes associated with familial AD and exhibit impaired $\mathrm{LTP}^{28,29}$. To characterise LTP and synaptic plasticity in the hippocampi of these mice, we recorded field excitatory postsynaptic potentials (fEPSPs) in the CA1, and measured the phosphorylation and surface expression of GluA1 subunits of AMPARs. The effects of stress were validated in vivo and ex vivo in experiments using the glucocorticoid receptor agonist dexamethasone.

\section{Results}

Acute stress rescues impaired LTP in the hippocampal CA1 region of AD mice. In the first set of experiments, we determined whether acute stress alters LTP in the CA1 region by recording fEPSPs in acutely prepared hippocampal slices from either 5 XFAD or Tg2576 mice (Fig. 1a). The baseline recordings were stable for $30 \mathrm{~min}$, with no significant difference between stressed and control unstressed mice. However, further recordings for 60 min following HFS revealed that LTP was not induced in slices from control 5XFAD $(n=6$ [six slices from six animals per group]) or control $\operatorname{Tg} 2576(n=6)$ mice (Fig. 1b,c, respectively). By contrast, LTP was induced by HFS in slices from stressed 5XFAD $[\mathrm{t}=-6.855, \mathrm{df}=9 ; p<0.01, n=6$, unpaired $t$ test; Fig. 1b] and stressed $\mathrm{Tg} 2576[\mathrm{t}=-11.135, \mathrm{df}=6 ; p<0.01, n=6$, unpaired $t$ test; Fig. $1 \mathrm{c}]$ mice. Additional experiments in slices from wild-type mice confirmed that LTP is induced by HFS in slices from unstressed control mice $(n=5)$ and that acute stress significantly enhances the magnitude of the LTP $[\mathrm{t}=-8.8, \mathrm{df}=9 ; p<0.01, n=5-6$, unpaired $t$ test; Supplementary Fig. 1] (Table 1). Altogether, these data confirm that acute stress potentiates LTP and suggest that acute stress can rescue impaired LTP in mouse models of AD. 


\begin{tabular}{|l|l|l|l|l|l|l|}
\hline & \multicolumn{3}{|l}{ fEPSP slope } & \multicolumn{2}{l|}{ sGluAl } & \multicolumn{2}{l|}{ pS845-GluA1 } \\
\cline { 2 - 7 } & C & S & C & S & C & S \\
\hline 5XFAD & $102 \pm 7 \%$ & $170 \pm 8 \%$ & $100 \%$ & $215 \pm 8 \%$ & $100 \%$ & $253 \pm 5 \%$ \\
\hline Tg2576 & $109 \pm 4 \%$ & $176 \pm 7 \%$ & $100 \%$ & $294 \pm 9 \%$ & $100 \%$ & $236 \pm 5 \%$ \\
\hline Wild type & $148 \pm 4 \%$ & $203 \pm 5 \%$ & $100 \%$ & $176 \pm 25 \%$ & $100 \%$ & $232 \pm 43 \%$ \\
\hline
\end{tabular}

Table 1. Effect of acute stress on LTP, Surface expression and phosphorylation of AMPA - GluA1.

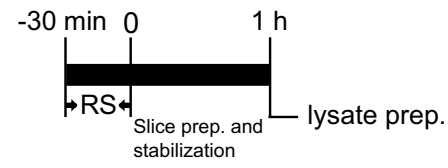

5XFAD

a

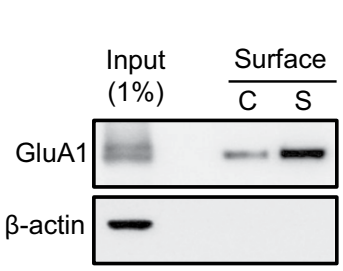

c

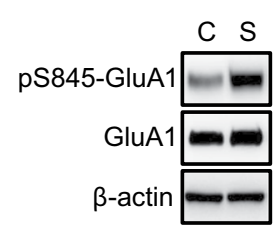



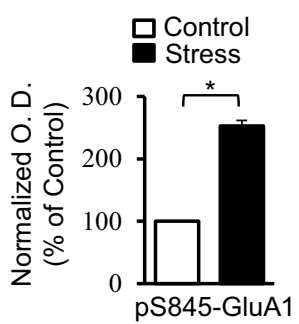



b



GluA1

(1\%) C S

$\beta$-actin
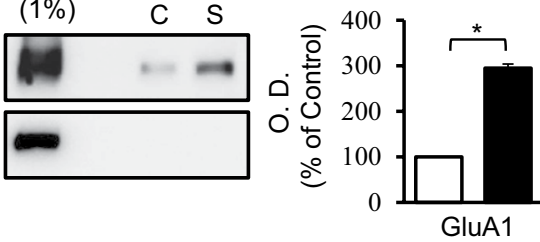

d
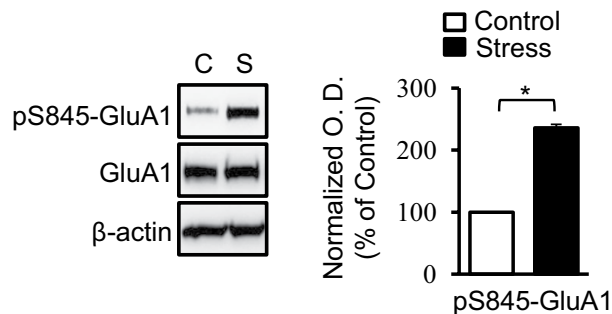

Figure 2. Acute stress induces phosphorylation and recruitment of GluA1 receptors to the cell surface. Representative immunoblots and densitometry analysis showing GluA1 surface expression in hippocampi of 5XFAD mice ( $n=4$ /group) (a) and Tg2576 mice ( $n=3$ /group) (b). Representative immunoblots and densitometry analysis showing the amount of pS845-GluA1 and total GluA1 in hippocampi from 5XFAD mice ( $n=5$ /group) (c) and Tg2576 mice ( $n=4$ /group) (d). C, unstressed control; S, stressed. Error bars indicate SEMs; $* P<0.01$. Full length blots are presented in Supplementary Fig. 3.

Acute stress increases surface expression and GluA1 phosphorylation. We next performed biotinylation assays to evaluate the surface expression of AMPAR GluA1 subunits in hippocampal tissues from control and acutely stressed AD model mice. Western blots revealed that the surface expression of GluA1 was higher in stressed mice than in controls for the 5XFAD model $[\mathrm{t}=-6.469, \mathrm{df}=9 ; p<0.01, n=4$, unpaired $t$ test; Figs 2a, S3] and the Tg2576 model [ $\mathrm{t}=-6.841, \mathrm{df}=4 ; p<0.01, n=3$, unpaired $t$ test; Figs $2 \mathrm{~b}, \mathrm{~S} 3]$. Similar results were obtained with wild-type mice exposed to acute stress [ $\mathrm{t}=-5.2, \mathrm{df}=4 ; p<0.05, n=3$, unpaired $t$ test; Figs S2a, S6].

The increase in surface expression was accompanied by an increase in phosphorylation at serine 845 (pS845). Western blotting analyses showed that exposure to acute stress increased the levels of pS845-GluA1 in hippocampi from 5XFAD mice $[\mathrm{t}=-3.730, \mathrm{df}=8 ; p<0.01, n=5$, unpaired $t$ test; Figs $2 \mathrm{c}, \mathrm{S} 3]$ and $\mathrm{Tg} 2576$ mice $[\mathrm{t}=-4.988, \mathrm{df}=6 ; p<0.01, n=4$, unpaired $t$ test; Figs $2 \mathrm{~d}, \mathrm{~S} 3]$. The acute stress-induced phosphorylation also occurred in wild-type mice $[\mathrm{t}=-17.5, \mathrm{df}=4 ; p<0.01, n=4$, unpaired $t$ test; Figs S2b, S6]. The total levels of GluA1 in the hippocampus did not differ between stressed and control animals in both models (Fig. 2c,d).

Sustained hippocampal LTP and GluA1 phosphorylation. To determine the time course of enhanced LTP and hippocampal GluA1 phosphorylation, we analysed fEPSPs 1, 3 and $5 \mathrm{~h}$ after the restraint stress (Fig. 3a). The magnitude of LTP in hippocampal slices prepared from stressed 5XFAD mice remained higher after 1 and $3 \mathrm{~h}[1 \mathrm{~h}: \mathrm{F}(3,17)=32.6 ; p<0.01$ and $3 \mathrm{~h}: p<0.01$ respectively, $\mathrm{n}=5-6$, one-way analysis of variance [ANOVA] with Scheffe test; Fig. 3b], but was not significantly different from controls after $5 \mathrm{~h}[5 \mathrm{~h}: \mathrm{F}(3,17)=32.6 ; p=0.882$, $n=6$, ANOVA with Scheffe test; Fig. 3b]. Similarly, Tg2576 mice exhibited higher LTP magnitudes at 1 and $3 \mathrm{~h}$ 
a



b

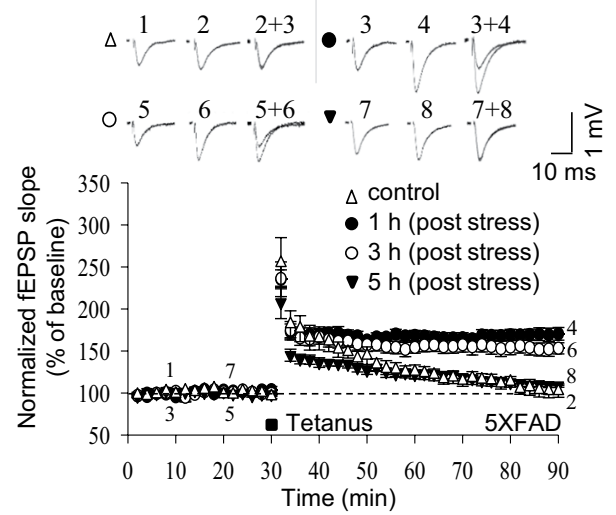

d
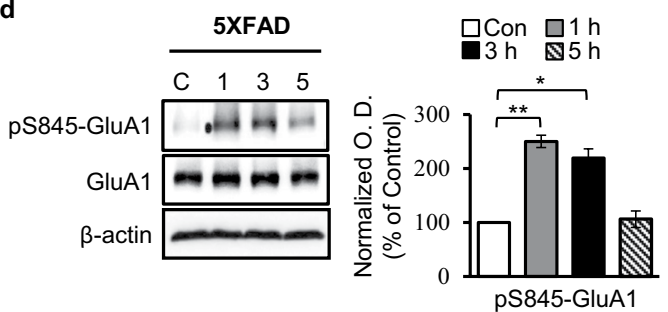

c

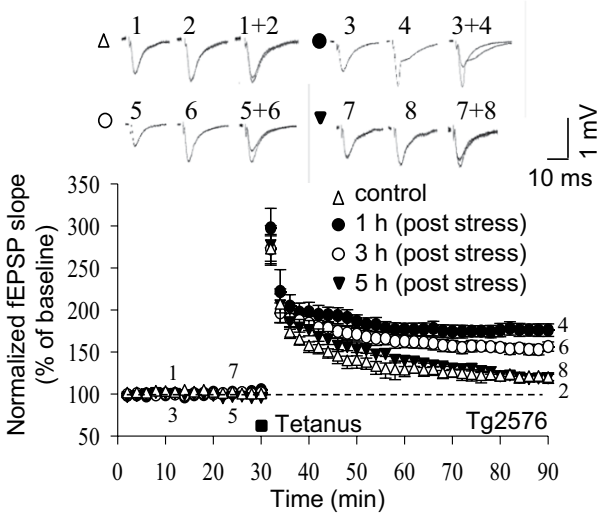

e



Figure 3. Acute stress rescues LTP and induces pS845-GluA1 expression in a time-dependent manner. (a) Schematic representation of the restraint stress experimental setup. Representative LTP magnitudes at 1, 3 and $5 \mathrm{~h}$ after stress; LTP induced by acute stress was maintained for $>3 \mathrm{~h}$ in 5XFAD (b) and Tg2576 (c) mice ( $n=5-6$ /group). Representative immunoblots and densitometry analysis showing the amount of pS845-GluA1 and total GluA1 in hippocampi from 5XFAD mice ( $n=5 /$ group) (d) and Tg2576 mice $(n=6 /$ group) (e). C, unstressed control; 1,3 and $5 \mathrm{~h}$ post-stress. Error bars indicate SEMs; $* P<0.05, * * P<0.01$. Full length blots are presented in Supplementary Fig. 4.

after acute stress $[1 \mathrm{~h}: \mathrm{F}(3,18)=24.7 ; p<0.01$ and $3 \mathrm{~h}: p<0.01$ respectively, $\mathrm{n}=5-6$, ANOVA with Scheffe test; Fig. 3c], with fEPSP magnitudes that did not differ from control slices at $5 \mathrm{~h}[5 \mathrm{~h}: \mathrm{F}(3,18)=24.7 ; p=0.992, n=6$, ANOVA with Scheffe test; Fig. 3c].

Western blot analyses of hippocampal samples taken from 5XFAD mice indicated that the levels of pS845-GluA1 were elevated 1 and $3 \mathrm{~h}$ after the restraint stress $[1 \mathrm{~h}: \mathrm{F}(3,11)=13.4 ; p<0.01$ and $3 \mathrm{~h}: p<0.05$ respectively, $\mathrm{n}=5$, ANOVA with Games-Howell test; Figs 3d, S4] and returned to control levels by $5 \mathrm{~h}$ [5 h: $\mathrm{F}(3,11)=13.4 ; p=1.0, n=6$, ANOVA with Games-Howell test; Figs 3d, S4]. Similarly, pS845-GluA1 levels from Tg2576 mice were increased at 1 and $3 \mathrm{~h}$ after the restraint stress $[1 \mathrm{~h}: \mathrm{F}(3,7)=7.6 ; p<0.01$ and $3 \mathrm{~h}: p<0.05$ respectively, $\mathrm{n}=6$, ANOVA with LSD test; Figs 3e, S4], with control levels observed at $5 \mathrm{~h}$ [ $5 \mathrm{~h}$ : $\mathrm{F}(3,7)=7.6 ; p=0.946, n=6$, ANOVA with LSD test; Figs 3e, S4]. Collectively, these results indicate that the acute stress-enhanced LTP induction and GluAl phosphorylation persisted for more than $3 \mathrm{~h}$ in two mouse models of AD.

Glucocorticoid receptor agonist mimics the acute stress effects in AD mouse models. We next evaluated whether a glucocorticoid receptor agonist would induce effects similar to acute restraint stress on hippocampal LTP in 5XFAD and Tg2576 mice. Acutely prepared hippocampal slices were perfused with $200 \mathrm{nM}$ dexamethasone (a dose that enhances LTP in mice ${ }^{26}$ ) while fEPSP recordings were acquired. Baseline levels were similar between treated and untreated slices. fEPSP slopes following HFS were significantly higher in slices treated with $200 \mathrm{nM}$ dexamethasone than in untreated slices from 5XFAD mice $[\mathrm{t}=-7.1, \mathrm{df}=9 ; p<0.01, n=6$, unpaired $t$ test; Fig. 4a] and Tg2576 mice $[\mathrm{t}=-7.2, \mathrm{df}=8 ; p<0.01, n=6$, unpaired $t$ test; Fig. 4b], demonstrating enhanced LTP in the presence of the glucocorticoid agonist.

Results from the surface biotinylation assays revealed that $30 \mathrm{~min}$ dexamethasone treatment significantly increased the surface levels of GluA1 in hippocampal tissues from $5 \mathrm{XFAD}[\mathrm{t}=-4.4, \mathrm{df}=6 ; p<0.01$, $n=6$, unpaired $t$ test; Figs $4 \mathrm{c}, \mathrm{S} 5]$ and $\mathrm{Tg} 2576[\mathrm{t}=-29.3, \mathrm{df}=4 ; p<0.01, n=5$, unpaired $t$ test; Figs $4 \mathrm{~d}$, S5]. Accordingly, the levels of pS845-GluA1 in 5XFAD $[\mathrm{t}=-9.4, \mathrm{df}=4 ; p<0.01, n=5$, unpaired $t$ test; Figs $4 \mathrm{e}$, S5] and $\operatorname{Tg} 2576[\mathrm{t}=-4.2, \mathrm{df}=4 ; p<0.01, n=4$, unpaired $t$ test; Figs $4 \mathrm{f}, \mathrm{S} 5]$ mice were significantly increased by dexamethasone treatment. Dexamethasone treatment did not affect total GluA1 levels (Figs 4e,f, S5). These 


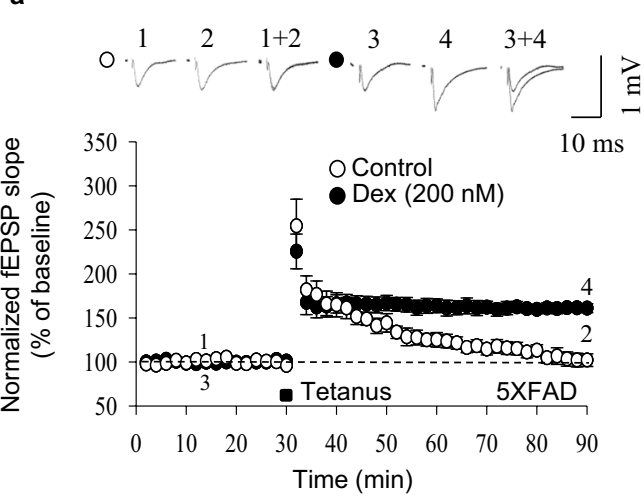

b

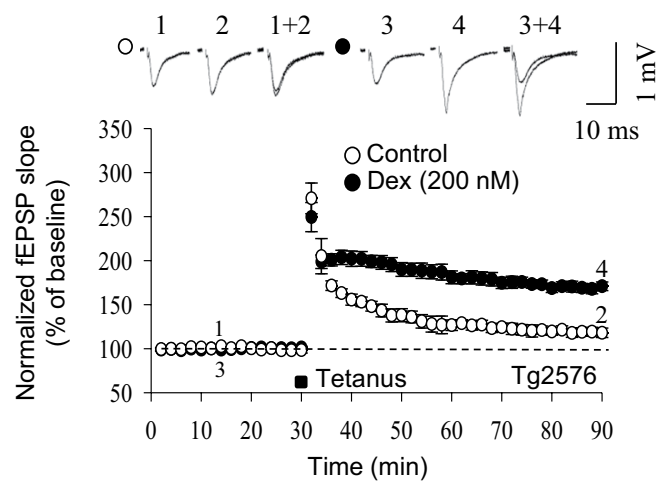

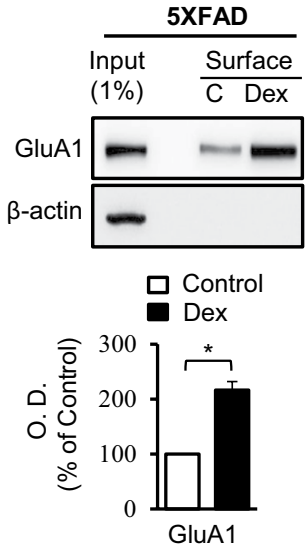

d



e

$\operatorname{Dex}(200 \mathrm{nM})-+$

pS845-GluA1 $=-$

GluA1 $-\infty$

$\beta$-actin -

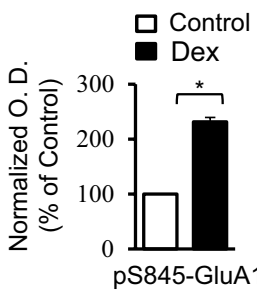

f



Figure 4. Glucocorticoid receptors regulate acute stress-mediated LTP and pS845-GluA1 expression in AD mice Representative LTP analyses in hippocampal slices treated with dexamethasone (Dex [200 nM]) from 5XFAD ( $n=6$ /group) (a) and Tg2576 ( $n=5$ /group) mice (b). Representative immunoblots and densitometry analyses showing GluA1 surface expression in hippocampi from 5XFAD ( $n=6 /$ group) (c) and Tg2576 ( $n=5 /$ group) (d) mice. Representative immunoblots and densitometry analyses showing pS845-GluA1 and total GluA1 expression in hippocampi from $5 X F A D$ ( $n=5$ /group) (e) and Tg2576 ( $n=4 /$ group) mice (f). C, untreated control. Error bars indicate SEMs; $* P<0.01$. Full length blots are presented in Supplementary Fig. 5.

results support the previous observations on the effects of acute stress and glucocorticoids on hippocampal LTP enhancement in mice.

\section{Discussion}

The results of the present study show that exposure to $30 \mathrm{~min}$ of restraint stress reverses hippocampal LTP impairments and increases AMPAR GluA1 phosphorylation and surface expression. These effects persisted for more than $3 \mathrm{~h}$. Moreover, we confirmed that the effects of the stress were due to glucocorticoid activation, as treatment with dexamethasone produced similar results. These findings suggest a beneficial role of acute stress on hippocampal synaptic plasticity.

Previous studies have shown that acute stress facilitates LTP by modulating glutamatergic receptors. For example, it has been shown that acute stress induced enhancement of glutamatergic transmission depends on the modifications of NMDA and AMPA receptors ${ }^{25}$. In mice, exposure to 30 min restraint stress shown to elevate hippocampal CA1 LTP levels through increased surface expression and GluA1 phosphorylation ${ }^{26}$. Furthermore, acute stress induced by immobilization and tail-shock, reported to increase the excitability of CA1 pyramidal neurons ${ }^{30}$, which plays an essential role in the hippocampal LTP induction. Acute stress was also shown to facilitate long-term potentiation of population spikes (PS-LTP) in the CA1 region of mouse hippocampus ${ }^{31}$. Similarly, acute restraint stress elevates acetylcholinesterase levels and enhances LTP in the CA1 region of the hippocampus $^{32}$. Consistent with these observations, we also found increased surface expression of GluA1 containing AMPAR and elevated LTP in transgenic mice hippocampus which furtherly supports the LTP enhancing effect of acute stress.

A stressful brief period of swimming or immobilization elevates CaMKII levels, which are essential for AMPAR trafficking and LTP maintenance, in rat hippocampus ${ }^{33,34}$. We show here that acute restraint stress enhanced surface expression of GluA1 subunits of AMPARs as well as their phosphorylation. These support the phosphorylation of GluA1 subunit at S845 and their homomeric assembly in AMPARs on the membrane surface as a mechanism by which restraint stress induces LTP $^{26}$. Notably, GluA1 phosphorylation and AMPAR 
surface expression are reported to be lower in mice overexpressing APP or exposed to A $\beta$. For instance, exposure to soluble oligomers of $\mathrm{A} \beta$ results in dephosphorylation and reduced surface expression of GluAl containing AMPARs ${ }^{17}$. Overexpression of APP has been shown to decrease synaptic AMPARs and depress synaptic transmission $^{35}$. Moreover, mice overexpressing APP/PS1 gene, showed to express lower levels of AMPARs ${ }^{36}$. Previous reports on the effect of acute stress in $\mathrm{AD}$ mice showed increased levels of amyloid production which results in decreased glutamatergic transmission and LTP impairment ${ }^{37,38}$. However, the stress paradigms used in these studies are longer, such as several hours to several days. In the present study, we show that acute stress for $30 \mathrm{~min}$ enhanced the phosphorylation and surface expression of AMPARs in the hippocampi of 5XFAD and Tg2576 mice for more than $3 \mathrm{~h}$. The fact that total levels of these receptor subunits were unchanged in stressed mice rules out the possibility of new receptor synthesis in response to acute stress.

Corticosterone is the major glucocorticoid responsible for the effects of stress ${ }^{39}$. Whereas increased or sustained glucocorticoid levels impair long-term memory, acute exposure enhances memory and cognitive performance. In mice, acute stress for $15 \mathrm{~min}$ showed to elevate intra-hippocampal corticosterone levels up to $240 \mathrm{nM}^{40}$. In addition, $30 \mathrm{~min}$ exposure to corticosterone or dexamethasone at $200 \mathrm{nM}$ concentrations shown to enhance LTP induction, through facilitated AMPAR trafficking in rat hippocampus ${ }^{26}$. Similarly, a short exposure to corticosterone increases the surface mobility and synaptic content of the AMPAR GluA2 subunit in rat hippocampal neurons ${ }^{41}$. Accordingly, we showed that dexamethasone elevated the phosphorylation and surface expression of GluA1-containing AMPARs and enhanced LTP in the CA1 regions of 5XFAD and Tg2576 mice.

In summary, the present study demonstrated an alleviation of impaired LTP and synaptic plasticity in the hippocampal CA1 following acute stress in the AD mouse models. We show that acute restraint stress, via glucocorticoid activation, enhances LTP by facilitating AMPAR trafficking and excitatory synaptic transmission in this region. Thus, we suggest that these molecular alterations modulated by acute stress may benefit memory function and cognition in these $\mathrm{AD}$ mice.

\section{Materials and Methods}

Animals. Eleven male wild-type mice (C57BL/6 J, 7-8 weeks) and 23 Tg2576 (APP KM670/671NL, 8 months old; Taconic, Rensselaer, NY) and 24 5XFAD (APP KM670/671NL [Swedish], APP I716V [Florida], APP V717I [London], PSEN1 M146L, PSEN1 L286V, 4 months old; Jackson Laboratory, Bar Harbor, ME) male mice on a hybrid C57BL/6 J background were utilised for the experiments. Animals were housed in individually ventilated cages with free access to food and water. The animal room was controlled with a $12 \mathrm{~h} \mathrm{light/dark} \mathrm{cycle} \mathrm{(lights} \mathrm{on} \mathrm{at}$ 8:00 a.m.), and the temperature was maintained at $22-30^{\circ} \mathrm{C}$.

Restraint stress and hippocampal slice preparation. Mice were physically restrained in well-ventilated $50 \mathrm{ml}$ Falcon tubes for $30 \mathrm{~min}$. Control mice were housed in their usual cages under normal conditions. Animals were sacrificed immediately following restraint stress, (between 9:00 a.m. and 10:00 a.m.), and the brains were quickly removed and transferred to ice-cold artificial cerebrospinal fluid (aCSF; $124 \mathrm{mM} \mathrm{NaCl}, 3 \mathrm{mM} \mathrm{KCl}$,

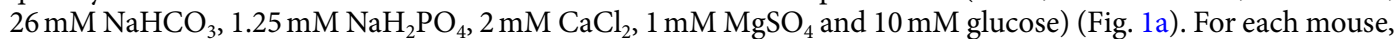
a mid-sagittal cut was made in the brain, and one hemisphere was returned to ice-cold aCSF until required. Transverse hippocampal slices ( $400 \mu \mathrm{m}$ thick) were cut using a McIlwain tissue chopper (Mickle Laboratory Engineering Co. Ltd., Guildford, UK) and allowed to stabilise in aCSF for $1 \mathrm{~h}$ with perfusion of $95 \% \mathrm{O}_{2}$ and $5 \%$ $\mathrm{CO}_{2}$ at room temperature.

Electrophysiology. Hippocampal slices recovered for approximately $60 \mathrm{~min}$ after the slice procedure to allow stable responses to be obtained. Two stimulating bipolar electrodes comprising $66 \mu \mathrm{M}$ twisted nichrome wire were set on the Schaffer collateral pathway (for LTP input) and subiculum region (for control input). Extracellular field potentials were recorded in the CA1 region using microcapillary electrodes containing $\mathrm{NaCl}$ $(3 \mathrm{M})$. Stimuli were delivered alternatively to the two electrodes $(0.016 \mathrm{~Hz}$ each $)$. After establishing a stable baseline for $30 \mathrm{~min}$, LTP was evoked by two trains of tetanic stimuli $(100 \mathrm{~Hz}$ for $1 \mathrm{~s}$ with a $30 \mathrm{~s}$ interval) and fEPSPs were recorded for at least $60 \mathrm{~min}$. The slope of the evoked field potential response was measured and expressed relative to the normalised preconditioning baseline. Data were collected by a NI USB-6251 data acquisition module (National Instruments, Austin, TX), amplified by an Axopatch 200B amplifier (Axon Instruments, Foster City, CA) and captured and analysed using WinLTP software (www.winltp.com).

Biotinylation and streptavidin pull-down assays. Surface biotinylation in acute slices was performed as described previously with some modifications ${ }^{42}$. Briefly, slices were washed twice in aCSF and then incubated in aCSF containing $1 \mathrm{mg} / \mathrm{ml}$ sulpho-NHS-SS-biotin for $45 \mathrm{~min}$ at $4{ }^{\circ} \mathrm{C}$ to label surface membrane proteins. Biotinylated tissue was then homogenised in lysis buffer containing $25 \mathrm{mM}$ Tris (pH 7.6), $150 \mathrm{mM} \mathrm{NaCl}, 1 \%$ NP-40, $1 \%$ sodium deoxycholate, $0.1 \%$ SDS, $1 \mathrm{mM} \mathrm{NaF}$ and a cocktail of protease inhibitors (Sigma-Aldrich, St. Louis, MO). The lysate was centrifuged at $11,000 \times g$ for $15 \mathrm{~min}$ at $4^{\circ} \mathrm{C}$ to remove nuclei and cellular debris. Total protein concentration was determined with a bicinchoninic acid assay (Pierce of Thermo Fisher Scientific, Waltham, MA). A small amount of the lysate was removed for later whole-cell analysis. Subsequently, $100 \mu \mathrm{l}$ of streptavidin beads (Thermo Fisher Scientific) was added to $600 \mu \mathrm{g}$ of protein lysate, and the mixture was placed on a rotator at $4^{\circ} \mathrm{C}$ for $2 \mathrm{~h}$. Samples were then washed five times in wash buffer ( $25 \mathrm{mM}$ Tris [pH 7.6], $150 \mathrm{nM}$ $\mathrm{NaCl}, 0.5 \%$ Triton X-100), and the beads were pulled down after each wash by gentle centrifugation. Bound proteins were eluted in $2 \times$ SDS reducing buffer and gently heated at $60^{\circ} \mathrm{C}$ for $30 \mathrm{~min}$. The resulting supernatant was transferred to new tubes and heated at $90^{\circ} \mathrm{C}$ for $5 \mathrm{~min}$ before gel loading.

Immunoblotting. Hippocampal tissue lysates were prepared using radio immune precipitation buffer with protease inhibitors (Cell Biolabs, Inc., San Diego, CA). Protein concentrations were determined with a bicinchoninic acid assay. Proteins were resolved in $10-12 \%$ gels and transferred to polyvinylidene difluoride 


\begin{tabular}{|l|l|l|l|l|l|l|}
\hline & \multicolumn{3}{|l|}{ fEPSP slope } & \multicolumn{2}{l|}{ sGluA1 } & \multicolumn{2}{l|}{ pS845-GluA1 } \\
\cline { 2 - 7 } & C & Dex & C & Dex & C & Dex \\
\hline 5XFAD & $102 \pm 7 \%$ & $161 \pm 5 \%$ & $100 \%$ & $217 \pm 1 \%$ & $100 \%$ & $232 \pm 8 \%$ \\
\hline Tg2576 & $118 \pm 5 \%$ & $171 \pm 4 \%$ & $100 \%$ & $250 \pm 8 \%$ & $100 \%$ & $214 \pm 8 \%$ \\
\hline
\end{tabular}

Table 3. Effect of dexamethasone on LTP, Surface expression and phosphorylation of AMPA - GluA1.

\begin{tabular}{|c|c|c|c|c|c|c|c|c|}
\hline & \multicolumn{4}{|c|}{ fEPSP slope } & \multicolumn{4}{|c|}{ pS845-GluA1 } \\
\hline & \multirow[b]{2}{*}{ control } & \multicolumn{3}{|c|}{ post stress } & \multirow[b]{2}{*}{ control } & \multicolumn{3}{|l|}{ post stress } \\
\hline & & $1 \mathrm{~h}$ & $3 \mathrm{~h}$ & $5 \mathrm{~h}$ & & $1 \mathrm{~h}$ & $3 \mathrm{~h}$ & $5 \mathrm{~h}$ \\
\hline 5XFAD & $102 \pm 7 \%$ & $170 \pm 8 \%$ & $153 \pm 7 \%$ & $108 \pm 2 \%$ & $100 \%$ & $250 \pm 8 \%$ & $219 \pm 1 \%$ & $106 \pm 1 \%$ \\
\hline $\operatorname{Tg} 2576$ & $118 \pm 5 \%$ & $176 \pm 7 \%$ & $156 \pm 5 \%$ & $120 \pm 5 \%$ & $100 \%$ & $224 \pm 9 \%$ & $194 \pm 1 \%$ & $110 \pm 2 \%$ \\
\hline
\end{tabular}

Table 2. Time dependent effect of acute stress on LTP, and phosphorylation of AMPA - GluA1 levels.

membranes (Millipore, Bedford, MA). After blocking with $1 \times$ RapidBlock solution (Amresco of VWR, Radnor, PA) for $5 \mathrm{~min}$ at room temperature, membranes were incubated with the following primary antibodies (Cell Signaling Technology, Danvers, MA) overnight at $4^{\circ} \mathrm{C}$ : anti-pS845-GluA1 (1:1,000 dilution), anti-GluA1 $(1: 1,000)$ and anti- $\beta$-actin $(1: 1,000)$. After washing, the membranes were then incubated with horseradish peroxidase-conjugated secondary antibodies $(1: 5,000)$ in $1 \times$ RapidBlock solution for $1 \mathrm{~h}$ at room temperature and visualised using an enhanced chemiluminescence detection system (Millipore, Bedford, MA). The optical density of immunoreactive bands was measured using ImageJ software (National Institutes of Health, Bethesda, $\mathrm{MD})$. The results were normalised to the quantity of $\beta$-actin in each sample lane.

Statistical analysis. All statistical graphs represent means \pm the standard errors of the means (SEMs). Data were analysed from one slice per mouse $(n=$ number of slices $=$ number of mice). Relative percentages of LTP and protein expressions were presented as tables at the end of the manuscript (Tables 1-3). Statistical analysis was performed either by a two-tailed unpaired Student's $t$ test to compare two groups or a one-way ANOVA with post-hoc test when $\geq 3$ groups were compared using SPSS 23.0 software. A $P$ value of $<0.05$ was considered statistically significant.

Study approval. All experiments and methods were performed in accordance with the relevant guidelines and regulations. Experiments involving animals followed approved protocols from the Institutional Animal Care and Use Committee of Chonnam National University.

\section{Data Availability}

The data sets generated and/or analysed during the present study are available from the corresponding author on reasonable request.

\section{References}

1. Shinohara, M. et al. Regional distribution of synaptic markers and APP correlate with distinct clinicopathological features in sporadic and familial Alzheimer's disease. Brain: a journal of neurology 137, 1533-1549, https://doi.org/10.1093/brain/awu046 (2014).

2. Gomez-Isla, T. et al. Neuronal loss correlates with but exceeds neurofibrillary tangles in Alzheimer's disease. Annals of neurology 41, 17-24, https://doi.org/10.1002/ana.410410106 (1997).

3. Hardy, J. \& Selkoe, D. J. The amyloid hypothesis of Alzheimer's disease: progress and problems on the road to therapeutics. Science 297, 353-356, https://doi.org/10.1126/science.1072994 (2002).

4. Walsh, D. M. et al. Naturally secreted oligomers of amyloid beta protein potently inhibit hippocampal long-term potentiation in vivo. Nature 416, 535-539, https://doi.org/10.1038/416535a (2002).

5. Shankar, G. M. et al. Amyloid-beta protein dimers isolated directly from Alzheimer's brains impair synaptic plasticity and memory. Nature medicine 14, 837-842, https://doi.org/10.1038/nm1782 (2008).

6. Bliss, T. V. \& Collingridge, G. L. A synaptic model of memory: long-term potentiation in the hippocampus. Nature 361, 31-39, https://doi.org/10.1038/361031a0 (1993).

7. Joels, M. et al. Effects of chronic stress on structure and cell function in rat hippocampus and hypothalamus. Stress 7, 221-231, https://doi.org/10.1080/10253890500070005 (2004).

8. Luscher, C. \& Malenka, R. C. NMDA receptor-dependent long-term potentiation and long-term depression (LTP/LTD). Cold Spring Harbor perspectives in biology 4, https://doi.org/10.1101/cshperspect.a005710 (2012).

9. Park, P. et al. The Role of Calcium-Permeable AMPARs in Long-Term Potentiation at Principal Neurons in the Rodent. Hippocampus. Frontiers in synaptic neuroscience 10, 42, https://doi.org/10.3389/fnsyn.2018.00042 (2018).

10. Jo, J. et al. Abeta(1-42) inhibition of LTP is mediated by a signaling pathway involving caspase-3, Akt1 and GSK-3beta. Nature neuroscience 14, 545-547, https://doi.org/10.1038/nn.2785 (2011).

11. Chapman, P. F. et al. Impaired synaptic plasticity and learning in aged amyloid precursor protein transgenic mice. Nature neuroscience 2, 271-276, https://doi.org/10.1038/6374 (1999).

12. Larson, J., Lynch, G., Games, D. \& Seubert, P. Alterations in synaptic transmission and long-term potentiation in hippocampal slices from young and aged PDAPP mice. Brain research 840, 23-35 (1999).

13. Cantanelli, P. et al. Age-Dependent Modifications of AMPA Receptor Subunit Expression Levels and Related Cognitive Effects in 3xTg-AD Mice. Frontiers in aging neuroscience 6, 200, https://doi.org/10.3389/fnagi.2014.00200 (2014). 
14. Hsieh, H. et al. AMPAR removal underlies Abeta-induced synaptic depression and dendritic spine loss. Neuron $\mathbf{5 2}$, 831-843, https:// doi.org/10.1016/j.neuron.2006.10.035 (2006).

15. Zhao, D., Watson, J. B. \& Xie, C.-W. Amyloid $\beta$ Prevents Activation of Calcium/Calmodulin-Dependent Protein Kinase II and AMPA Receptor Phosphorylation During Hippocampal Long-Term Potentiation. Journal of Neurophysiology 92, 2853-2858, https:// doi.org/10.1152/jn.00485.2004 (2004).

16. Gu, Z., Liu, W. \& Yan, Z. \{beta\}-Amyloid impairs AMPA receptor trafficking and function by reducing Ca2+/calmodulin-dependent protein kinase II synaptic distribution. The Journal of biological chemistry 284, 10639-10649, https://doi.org/10.1074/jbc. M806508200 (2009).

17. Minano-Molina, A. J. et al. Soluble oligomers of amyloid-beta peptide disrupt membrane trafficking of alpha-amino-3-hydroxy-5methylisoxazole-4-propionic acid receptor contributing to early synapse dysfunction. The Journal of biological chemistry $\mathbf{2 8 6}$, 27311-27321, https://doi.org/10.1074/jbc.M111.227504 (2011).

18. Li, S. et al. Soluble Abeta oligomers inhibit long-term potentiation through a mechanism involving excessive activation of extrasynaptic NR2B-containing NMDA receptors. The Journal of neuroscience: the official journal of the Society for Neuroscience 31, 6627-6638, https://doi.org/10.1523/JNEUROSCI.0203-11.2011 (2011).

19. Srivareerat, M., Tran, T. T., Alzoubi, K. H. \& Alkadhi, K. A. Chronic Psychosocial Stress Exacerbates Impairment of Cognition and Long-Term Potentiation in $\beta$-Amyloid Rat Model of Alzheimer's Disease. Biological Psychiatry 65, 918-926, https://doi. org/10.1016/j.biopsych.2008.08.021 (2009)

20. Pavlides, C., Nivon, L. G. \& McEwen, B. S. Effects of chronic stress on hippocampal long-term potentiation. Hippocampus 12, 245-257, https://doi.org/10.1002/hipo.1116 (2002)

21. Alfarez, D. N., Joels, M. \& Krugers, H. J. Chronic unpredictable stress impairs long-term potentiation in rat hippocampal CA1 area and dentate gyrus in vitro. The European journal of neuroscience 17, 1928-1934 (2003)

22. Gerges, N. Z., Aleisa, A. M., Schwarz, L. A. \& Alkadhi, K. A. Reduced basal CaMKII levels in hippocampal CA1 region: possible cause of stress-induced impairment of LTP in chronically stressed rats. Hippocampus 14, 402-410, https://doi.org/10.1002/ hipo.10193 (2004).

23. Kallarackal, A. J. et al. Chronic Stress Induces a Selective Decrease in AMPA Receptor-Mediated Synaptic Excitation at Hippocampal Temporoammonic-CA1 Synapses. The Journal of Neuroscience 33, 15669-15674, https://doi.org/10.1523/jneurosci.2588-13.2013 (2013).

24. Yuen, E. Y. et al. Repeated stress causes cognitive impairment by suppressing glutamate receptor expression and function in prefrontal cortex. Neuron 73, 962-977, https://doi.org/10.1016/j.neuron.2011.12.033 (2012).

25. Yuen, E. Y. et al. Acute stress enhances glutamatergic transmission in prefrontal cortex and facilitates working memory. Proceedings of the National Academy of Sciences of the United States of America 106, 14075-14079, https://doi.org/10.1073/pnas.0906791106 (2009).

26. Whitehead, G. et al. Acute stress causes rapid synaptic insertion of $\mathrm{Ca} 2+-$ permeable AMPA receptors to facilitate long-term potentiation in the hippocampus. Brain: a journal of neurology 136, 3753-3765, https://doi.org/10.1093/brain/awt293 (2013).

27. Kim, K. S. \& Han, P. L. Optimization of chronic stress paradigms using anxiety- and depression-like behavioral parameters. Journal of neuroscience research 83, 497-507, https://doi.org/10.1002/jnr.20754 (2006).

28. Kimura, R. \& Ohno, M. Impairments in remote memory stabilization precede hippocampal synaptic and cognitive failures in 5XFAD Alzheimer mouse model. Neurobiology of disease 33, 229-235, https://doi.org/10.1016/j.nbd.2008.10.006 (2009).

29. Crouzin, N. et al. Area-specific alterations of synaptic plasticity in the 5XFAD mouse model of Alzheimer's disease: dissociation between somatosensory cortex and hippocampus. PloS one 8, e74667, https://doi.org/10.1371/journal.pone.0074667 (2013).

30. Weiss, C., Sametsky, E., Sasse, A., Spiess, J. \& Disterhoft, J. F. Acute stress facilitates trace eyeblink conditioning in C57BL/6 male mice and increases the excitability of their CA1 pyramidal neurons. Learning \& memory 12, 138-143, https://doi.org/10.1101/ $\operatorname{lm} .89005$ (2005).

31. Blank, T., Nijholt, I., Eckart, K. \& Spiess, J. Priming of long-term potentiation in mouse hippocampus by corticotropin-releasing factor and acute stress: implications for hippocampus-dependent learning. The Journal of neuroscience: the official journal of the Society for Neuroscience 22, 3788-3794, 20026289 (2002)

32. Nijholt, I. et al. Stress-induced alternative splicing of acetylcholinesterase results in enhanced fear memory and long-term potentiation. Molecular Psychiatry 9, 174, https://doi.org/10.1038/sj.mp.4001446 (2003).

33. Ahmed, T., Frey, J. U. \& Korz, V. Long-Term Effects of Brief Acute Stress on Cellular Signaling and Hippocampal LTP. The Journal of Neuroscience 26, 3951-3958, https://doi.org/10.1523/jneurosci.4901-05.2006 (2006).

34. Suenaga, T., Morinobu, S., Kawano, K., Sawada, T. \& Yamawaki, S. Influence of immobilization stress on the levels of CaMKII and phospho-CaMKII in the rat hippocampus. The international journal of neuropsychopharmacology 7, 299-309, https://doi. org/10.1017/S1461145704004304 (2004).

35. Hsieh, H. et al. AMPAR Removal Underlies A $\beta$-Induced Synaptic Depression and Dendritic Spine Loss. Neuron 52, 831-843, https://doi.org/10.1016/j.neuron.2006.10.035 (2006).

36. Chang, E. H. et al. AMPA receptor downscaling at the onset of Alzheimer's disease pathology in double knockin mice. Proceedings of the National Academy of Sciences of the United States of America 103, 3410-3415, https://doi.org/10.1073/pnas.0507313103 (2006).

37. Kang, J. E., Cirrito, J. R., Dong, H., Csernansky, J. G. \& Holtzman, D. M. Acute stress increases interstitial fluid amyloid-beta via corticotropin-releasing factor and neuronal activity. Proceedings of the National Academy of Sciences of the United States of America 104, 10673-10678, https://doi.org/10.1073/pnas.0700148104 (2007).

38. Baglietto-Vargas, D. et al. Short-term modern life-like stress exacerbates Abeta-pathology and synapse loss in 3xTg-AD mice. Journal of neurochemistry 134, 915-926, https://doi.org/10.1111/jnc.13195 (2015).

39. Hill, E. E. et al. Exercise and circulating cortisol levels: the intensity threshold effect. Journal of endocrinological investigation 31, 587-591, https://doi.org/10.1007/BF03345606 (2008).

40. Chauveau, F. et al. Rapid stress-induced corticosterone rise in the hippocampus reverses serial memory retrieval pattern. Hippocampus 20, 196-207, https://doi.org/10.1002/hipo.20605 (2010).

41. Groc, L., Choquet, D. \& Chaouloff, F. The stress hormone corticosterone conditions AMPAR surface trafficking and synaptic potentiation. Nature neuroscience 11, 868-870, https://doi.org/10.1038/nn.2150 (2008).

42. Thomas-Crusells, J., Vieira, A., Saarma, M. \& Rivera, C. A novel method for monitoring surface membrane trafficking on hippocampal acute slice preparation. Journal of neuroscience methods 125, 159-166 (2003).

\section{Acknowledgements}

This work was funded by the Pioneer Research Center Program through the National Research Foundation of Korea funded by the Ministry of Science, ICT \& Future Planning (2014M3C1A3053029), and the Cooperative Research Program for Agriculture Science \& Technology Development (PJ01255102 and PJ012551042019). 


\section{Author Contributions}

The study was conceived by J.J. The experiments were designed and carried out by M.W. and V.S.R. The manuscript was written by V.S.R. and the final version was approved by J.J. All authors read and approved the final manuscript.

\section{Additional Information}

Supplementary information accompanies this paper at https://doi.org/10.1038/s41598-019-47452-6.

Competing Interests: The authors declare no competing interests.

Publisher's note: Springer Nature remains neutral with regard to jurisdictional claims in published maps and institutional affiliations.

(c) (i) Open Access This article is licensed under a Creative Commons Attribution 4.0 International License, which permits use, sharing, adaptation, distribution and reproduction in any medium or format, as long as you give appropriate credit to the original author(s) and the source, provide a link to the Creative Commons license, and indicate if changes were made. The images or other third party material in this article are included in the article's Creative Commons license, unless indicated otherwise in a credit line to the material. If material is not included in the article's Creative Commons license and your intended use is not permitted by statutory regulation or exceeds the permitted use, you will need to obtain permission directly from the copyright holder. To view a copy of this license, visit http://creativecommons.org/licenses/by/4.0/.

(C) The Author(s) 2019 